\title{
Isotopic Composition of Gadolinium and Neutron-Capture Effects in Some Meteorites ${ }^{1}$
}

\author{
O. Eugster, F. Tera, D. S. Burnett and G. J. Wasserburg \\ Charles Arms Laboratory of Geological Sciences \\ California Institute of Technology, Pasadena, California 91109
}

\begin{abstract}
The isotopic composition of Gd in one chondrite, two achondrites, and the silicate inclusions of two iron meteorites has been determined. When corrected for mass discrimination, Gd in all samples except the Norton County achondrite shows the same relative isotopic abundances as terrestrial Gd. These results set an upper limit of $3 \times 10^{15}$ neutrons per $\mathbf{c m}^{2}$ on a differential integrated thermal neutron irradiation of the earth and these meteorites. Neutron-capture effects are present in Gd extracted from the Norton County achondrite. These most probably have been produced by secondary neutrons during the exceptionally long cosmic ray exposure of this large stone meteorite. The isotopic anomalies correspond to an integrated thermal neutron flux of $(6.3 \pm 0.9) \times 10^{15}$ neutrons per $\mathrm{cm}^{2}$. The percent abundances of terrestrial Gd found in our work for $\mathrm{Gd}^{160}, \mathrm{Gd}^{158}, \mathrm{Gd}^{157}, \mathrm{Gd}^{166}, \mathrm{Gd}^{155}$, $\mathrm{Gd}^{154}$, and $\mathrm{Gd}^{152}$ are 21.863, 24.835, 15.652, 20.466, $14.800,2.1809$, and 0.2029 , respectively. Because of the higher precision, these abundances should replace the currently accepted values.
\end{abstract}

\section{INTRODUCTION}

The large isotopic cross sections of $\mathbf{G d}^{107}$ and $\mathrm{Gd}^{155}$ for thermal neutrons $(254,000$ barns and 60,000 barns, respectively) [Møller et al., 1960] indicate that these isotopes can serve as sensitive indicators of the integrated thermal neutron exposures of natural samples.

In comparing the isotopic composition of Gd in terrestrial samples, meteorites, and lunar material, at least two possible sources for differences have to be considered: (1) a neutron irradiation in the early history of the solar system that was different for terrestrial, meteoritic, and lunar samples and (2) a flux of thermal neutrons produced by moderation of secondary cosmic ray neutrons.

Two factors enter into a general discussion of $\mathrm{Gd}$ isotopic variations due to primordial irradiations: (1) the possibility of postirradiation mixing of irradiated and unirradiated material and (2) the magnitude of the integrated neutron flux. At present no positive evidence for such irradiations exists (see Burnett et al. [1965, 1966] for detailed discussions). For the case of a very high neutron exposure, e.g., as in the

\footnotetext{
1 Division of Geological Sciences Contribution No. 1697.
}

Copyright @ 1970 by the American Geophysical Union. model proposed by Fowler et al. [1962] (FGH model), $\mathrm{Gd}^{15 \pi}$ is totally depleted in the irradiated material; consequently, isotopic variations can result only from differences in the mixing ratios of irradiated and unirradiated material. Previous measurements in four stone meteorites by Murthy and Schmitt [1963] showed that meteoritic and terrestrial Gd had the same isotopic composition to within about $1 \%$. For the FGH model, these data allow limits of about $20 \%$ to be set for differences in the mixing ratio of irradiated and unirradiated material for terrestrial and meteoritic samples.

Alternatively, it can be assumed that all meteoritic and terrestrial material were subjected to an irradiation while in a highly dispersed state (i.e., a 'uniform irradiation' in the sense of Burnett et al. [1966]). In this case an upper limit on the differential thermal neutron exposure of the Gd in terrestrial material and in meteorites can be made. The data of Murthy and Schmitt [1963] allow an upper limit of $4 \times 10^{16}$ neutrons per $\mathrm{cm}^{2}$ for a differential thermal neutron irradiation to be set.

The neutron-capture effects that we shall describe were recognized by Daniels [1953] as an interesting possibility in natural samples.

Because of the great increase in instrumental precision now available [Wasserburg et al., 
1969], and because we have been able to increase the ionization efficiency by about a factor of 50 (see section 2 under Experimental Procedure), it was deemed desirable to reinvestigate this problem. For this purpose, a variety of different meteorite classes were studied. Four criteria were used in selecting the meteorites investigated. (1) In order to study the question of a differential early irradiation of meteoritic and terrestrial matter, the Pasamonte achondrite and the Forest City chondrite, both with a low exposure age (see Table 1), were chosen in an attempt to avoid cosmic ray produced Gd anomalies. (2) The silicate inclusions of the Weekeroo Station and the Copiapo irons were investigated because previous measurements (D. D. Bogard, J. Huneke, D. S. Burnett, and G. J. Wasserburg, unpublished data, 1969) had shown that large concentrations of neutroncapture $\mathrm{Kr}^{80,}$ and $\mathrm{Xe}^{203}$ are present in silicate inclusions from iron meteorites. (3) The Norton County achondrite was chosen on the basis of its high exposure age and its very high recovered weight. The latter fact promises a high slowing down density for secondary spallation-produced neutrons. (4) An attempt was made to sample the principle meteorite classes.

\section{Experimental Procedure}

1. Chemical separation. All samples were dissolved in $\mathrm{HClO}_{4}$ and $\mathrm{HF}$, typically $1 \mathrm{ml}$ of each, evaporated to dryness in a stream of filtered nitrogen and redissolved in a few $\mathrm{ml}$ of
$4 \mathrm{~N} \mathrm{HCl}$. This solution was again evaporated to dryness, the residue dissolved in $2 \mathrm{~N} \mathrm{HCl}$, and the solution stored in a polyethylene bottle.

Gd was separated by ion exchange in a twocolumn operation. An aliquot corresponding to a 50-100 mg solid sample was taken, evaporated to dryness, and then brought into solution in $2 \mathrm{ml}$ of $1.5 \mathrm{~N} \mathrm{HCl}$, which was loaded onto a $20 \times 1 \mathrm{~cm}$ cation-exchange column made from $\mathrm{SiO}_{2}$ glass, packed with Dowex $50 \times 8,100-200$ mesh resin. The resin height after preconditioning with $300 \mathrm{ml} 4 N \mathrm{HCl}$ was $17 \mathrm{~cm}$. Most of the rare earths were separated from all major constituents by elution with $4 N \mathrm{HCl}$ and collected in the fraction between 40 and $65 \mathrm{ml}$. This fraction was evaporated to dryness, redissolved in $0.8 \mathrm{~N} \mathrm{HCl}$ and loaded onto the second ion-exchange column.

The purpose of this second column was to separate $\mathrm{Gd}$ from the other rare earths. We used a $\mathrm{SiO}_{2}$ glass capillary with an inner diameter of $0.2 \mathrm{~cm}$ packed with carefully sized resin beads of 50-90 $\mu \mathrm{m}$ diameter separated from AG $50 \mathrm{~W}-\times 4,200-400$ mesh cation-exchange resin.

About $\mathbf{5 0} \mathrm{ml}$ of the sized resin was typically pretreated as follows: To remove traces of rare earths and $\mathrm{Ba}$, the resin was washed with one liter $4 N \mathrm{HCl}$, and the acid was removed with $\mathrm{H}_{2} \mathrm{O}$ (five times distilled). Thereupon, the resin was transformed to the $\mathrm{NH}_{4}^{+}$form with one liter of $0.4 M 2$-methyl lactic acid (E. H. Sargent and Co.) adjusted to $p \mathrm{H} 4.6$ with high purity concentrated $\mathrm{NH}_{4} \mathrm{OH}$. Tests with $\mathrm{Ce}^{144}$ tracer

TABLE 1. Some General Data on the Investigated Meteorites

\begin{tabular}{|c|c|c|c|c|c|}
\hline Meteorite & $\begin{array}{l}\text { Sample } \\
\text { Number }\end{array}$ & Classification" & $\begin{array}{c}\text { Recovered Weight, } \\
\mathbf{k g}^{\mathbf{a}}\end{array}$ & $\begin{array}{c}\text { Cosmic Ray } \\
\text { Exposure Age, } \\
\text { m.y. }\end{array}$ & $\begin{array}{c}\text { Gd } \\
\text { Concentration, } \\
\text { ppm }\end{array}$ \\
\hline Pasamonte & 297 yII & Eucrite & 4 & $4^{b}$ & $2.7^{\circ}$ \\
\hline $\begin{array}{l}\text { Weekeroo } \\
\text { Station }\end{array}$ & NC-R2 & Octahedrite & 94 & $\sim 600^{d}$ & $0.3^{f}$ \\
\hline Copiapo & & Octahedrite & 40 & & $0.2^{f}$ \\
\hline Norton County & $\begin{array}{l}523.3 \times \\
\text { Breccia IV }\end{array}$ & Aubrite & 1050 & $240^{\circ}$ & $\begin{array}{l}0.25^{f} \\
0.38^{e}\end{array}$ \\
\hline Forest City & $49 \mathrm{tI}$ & Chondrite & 122 & $4.6^{b}$ & $0.40^{\circ}$ \\
\hline
\end{tabular}

- $H e y[1966]$.

b Based on $\mathrm{He}^{2}$ concentration [Kirsten et al., 1963] and $\mathrm{He}^{8}$ production rate of $2 \times 10^{-8} \mathrm{~cm}^{2} \mathrm{STP} \mathrm{He} / \mathrm{g} \mathrm{m} . \mathrm{y}$.

- Begemann et al. [1957].

a Bogard et al. [1968].

- Haskin et al. [1966].

i This work (see section 3 under results). 
showed that this $p \mathrm{H}$ was high enough to prevent resin absorption of rare-earth elements that might have been present in the solution. On the other hand, any $\mathrm{Ba}$ present in the solution (see section on interfering ions) would have been strongly held on the resin. Finally, the resin, now in the $\mathrm{NH}_{4}^{+}$form, was washed with $\mathrm{H}_{2} \mathrm{O}$ to remove the reagent and the upper third of the resin that might have been contaminated with $\mathrm{Ba}$ was discarded.

About $1 \mathrm{~cm}^{3}$ of the remaining resin was packed into the $\mathrm{SiO}_{2}$ glass capillary and the resin height adjusted to about $32 \mathrm{~cm}$. Excess water was removed, and $0.2 M$ 2-methyl lactic acid, adjusted to $p \mathrm{H} 4.10$ with concentrated $\mathrm{NH}_{4} \mathrm{OH}$ was loaded onto the column. The column was allowed to drain for several hours, then a nitrogen pressure of about $0.14 \mathrm{~kg} / \mathrm{cm}^{2}$ over atmosphere was applied to the top of the column for about half an hour to bring the total volume of effluent to $10 \mathrm{ml}$. Excess solution and excess resin over exactly $30-\mathrm{cm}$ column height were removed with a pipette, and $0.15 \mathrm{ml} \mathrm{H}_{2} \mathrm{O}$ was passed through the column. The sample was loaded onto the column after it was prepared to this state. Elution was carried out with 0.2 $M$ 2-methyl lactic acid of $p H 4.10$ at a pressure of $0.14 \mathrm{~kg} / \mathrm{cm}^{2}$ over atmosphere resulting in a flow rate of one drop per minute. All separations were carried out at room temperature $\left(22 \pm 1^{\circ} \mathrm{C}\right)$. After each sample separation, the resin was discarded.

Repeated calibrations of the column with $\mathrm{Gd}^{1 \mathrm{sis}}$ tracer showed that the peak of the Gd elution curve was reproducible to within an average deviation of \pm 4 drops for a given batch of resin. However, a shift of 4 drops in the elution curve toward the Eu peak should be easily detected during the mass spectrometric analysis because of the high sensitivity of Eu. Only one column separation out of nine showed serious Eu contamination. The results of this separation were not accepted. Consequently, for reasons that are not understood, it appears that the Gd elution peaks for the samples analyzed were well within the \pm 4 -drop spread. Figure 1 shows that the procedure outlined above resulted in a good separation of Gd from the other rare earth elements.

Blank determinations showed that the Gd contamination introduced by the complete chemical processing was less than $3 \times 10^{-11}$ gram.

2. Mass spectrometry. The sample was evaporated to dryness, redissolved in a drop of $1.5 \mathrm{~N} \mathrm{HCl}$, and loaded on a rhenium filament. The amount of sample loaded is given in Tables 2-5. For most of the analyses, zone-refined, highpurity Re (The Rembar Company, Inc., Dobbs Ferry, N.Y.) was used after it had been outgassed for two hours at $\sim 2000^{\circ} \mathrm{C}$ in a vacuum

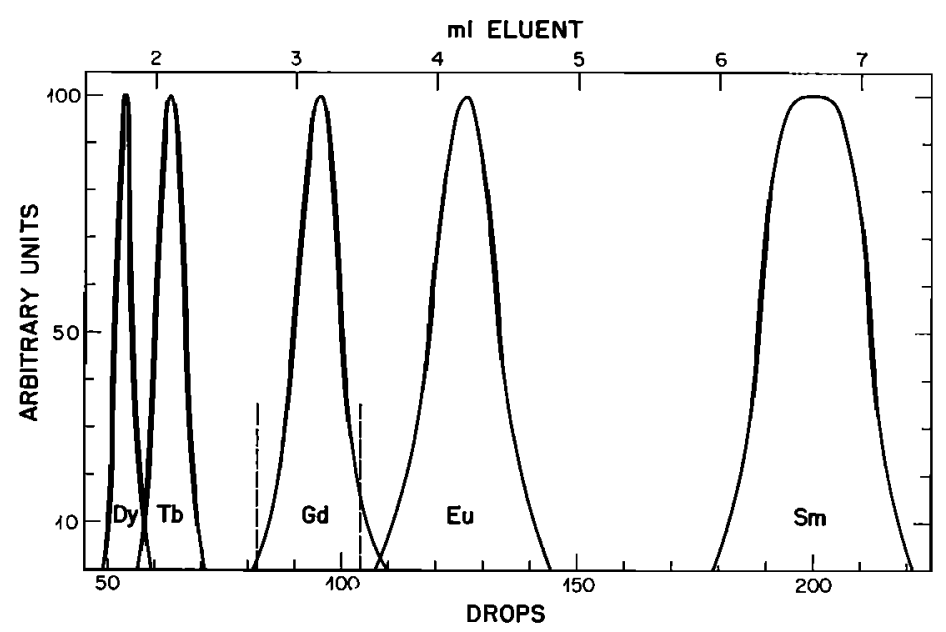

Fig. 1. Chemical separation of Gd from other rare earths by ion exchange. The eluent used was $0.2 M 2$-methyl lactic acid. The calibration was carried out with radioactive tracers of the elements shown. The vertical lines at drops 82 and 104 indicate the fraction of the Gd peak that was collected. It corresponds to about $96 \%$ of the total peak. 
TABLE 2. Isotopic Ratios of Terrestrial Gadolinium

\begin{tabular}{|c|c|c|c|c|c|c|c|c|c|}
\hline Run No.* & Sample & $\begin{array}{c}\text { Sample } \\
\text { Size, } \\
10^{-9} \mathrm{gram}\end{array}$ & $\begin{array}{c}\text { Sets of } 10 \\
\text { Ratios Taken } \\
\text { with Multiplier } \\
\text { (MP) or Faraday } \\
\text { Cup (FC) }\end{array}$ & $\frac{\text { Gd }^{158}}{\text { Gd }^{180}}$ & $\frac{G^{157}}{G d^{160}}$ & $\frac{G^{166^{b}}}{G^{160}}$ & $\frac{G^{168}}{G^{160}}$ & $\frac{\mathrm{Gd}^{154}}{\mathrm{Gd}^{100}}$ & $\frac{G^{162}}{G^{160}}$ \\
\hline $29 / 30 / 31$ (B) & Reagent Gd & $500-2000$ & $10(F C)$ & $\begin{array}{r}1.1359 \\
\pm 0006\end{array}$ & $\begin{array}{r}07155 \\
\pm .0006\end{array}$ & $\begin{array}{c}0.9361 \\
\ldots\end{array}$ & $\begin{array}{r}\mathbf{0 . 6 7 6 9} \\
\pm 0002\end{array}$ & $\begin{array}{r}0.09971 \\
\pm 00006\end{array}$ & . \\
\hline $30 / 31$ (B) & Reagent Gd & 2000 & 12 (MP) & $\begin{array}{r}1.1353 \\
\pm .0005\end{array}$ & $\begin{array}{r}07161 \\
\pm .0003\end{array}$ & $\begin{array}{c}09361 \\
\ldots\end{array}$ & $\begin{array}{r}06767 \\
\pm 0004\end{array}$ & $\begin{array}{l}0.09984 \\
\pm .00007\end{array}$ & $\begin{array}{r}000928 \\
\pm 00002\end{array}$ \\
\hline 51 (A) & Reagent Gd & 2000 & $10(\mathrm{FC})$ & $\begin{array}{r}1.13590 \\
\pm 00009\end{array}$ & $\begin{array}{r}0.71589 \\
\pm .00004\end{array}$ & $\begin{array}{c}09361 \\
\ldots\end{array}$ & $\begin{array}{r}\mathbf{0 . 6 7 6 9 5} \\
\pm .00009\end{array}$ & $\begin{array}{l}\cdots \\
\cdots\end{array}$ & $\begin{array}{l}\ldots \\
\cdots\end{array}$ \\
\hline 53 (A) & Reagent Gd & 2000 & $12(\mathrm{FC})$ & $\begin{array}{l}\ldots \\
\ldots\end{array}$ & $\begin{array}{l}\ldots \\
\ldots\end{array}$ & $\begin{array}{c}0.9361 \\
\ldots\end{array}$ & $\begin{array}{r}\mathbf{0 . 6 7 6 8 8} \\
\pm 00009\end{array}$ & $\begin{array}{r}0.09075 \\
\pm .00002\end{array}$ & $\begin{array}{l}\cdots \\
\cdots\end{array}$ \\
\hline $40(B)$ & Diabase $\mathrm{W}$ & 50 & 7 (MP) & $\begin{array}{r}1.1357 \\
\pm 0007\end{array}$ & $\begin{array}{r}0.7161 \\
\pm .0007\end{array}$ & $\begin{array}{c}09361 \\
\ldots\end{array}$ & $\begin{array}{r}06771 \\
\pm .0003\end{array}$ & $\begin{array}{r}009966 \\
\pm 00023\end{array}$ & $\begin{array}{c}000930^{\circ} \\
\pm .00004\end{array}$ \\
\hline \multicolumn{4}{|c|}{ Adopted value for terrestrial Gd } & $\begin{array}{r}1.13590 \\
\pm .00009\end{array}$ & $\begin{array}{r}0.71589 \\
\pm .00004\end{array}$ & $\begin{array}{c}09361 \\
\ldots\end{array}$ & $\begin{array}{r}067692 \\
\pm .00009\end{array}$ & $\begin{array}{r}0.09975 \\
\pm 00002\end{array}$ & $\begin{array}{r}0.00928 \\
\pm 00002\end{array}$ \\
\hline \multicolumn{4}{|c|}{ Collins et al. [1957] $\mathrm{d}$} & $\begin{array}{r}1.124 \\
\pm .011\end{array}$ & $\begin{array}{r}0.717 \\
\pm 007\end{array}$ & $\begin{array}{c}0.9361 \\
\ldots\end{array}$ & $\begin{array}{r}0.683 \\
\pm .007\end{array}$ & $\begin{array}{r}0.1004 \\
\pm 0013\end{array}$ & $\begin{array}{r}000915 \\
\pm 00050\end{array}$ \\
\hline
\end{tabular}

a (A) and (B) indicate that all sets that were averaged had standard deviations of the ratios $\mathrm{Gd}^{165-168} / \mathrm{Gd}^{260}$ of less than 0.25 or $0.4 \%$, respectively.

b Fractionation correction normalized to $\mathrm{Gd}^{156} / \mathrm{Gd}^{180}=0.9361$.

- See section 2 under Interfering Ions.

d Normalized to $\mathrm{Gd}^{268} / \mathrm{Gd}^{180}=0.9361$.

of $\sim 10^{-0}$ torr. After outgassing, no detectable Gd could be found by using the mass spectrometer. After the sample was loaded on the filament, the Gd was transformed to the oxide by heating the filament in air to $\sim 800^{\circ} \mathrm{C}$ for about one minute. The Lunatic 1 mass spectrometer [Wasserburg et al., 1969] was used for the analyses. GdO ions were obtained by using the single filament surface ionization technique. The stable ion beam was highest for a filament temperature of about $1400^{\circ} \mathrm{C}$. The yield for
GdO ions obtained by using this technique was about one order of magnitude better than that for Gd ions when a triple Re filament was used. Gd/GdO for the single filament was $<0.001$, and $\mathrm{Gd} / \mathrm{GdO}$ for the triple filament was about five. The ratio of $\mathrm{GdO}$ ions arriving at the collector to $\mathrm{Gd}$ atoms loaded on the filament was about $4 \times 10^{-4}$ for a sample size of $8 \times$ $10^{-8} \mathrm{gram} \mathrm{Gd}$. For smaller samples this ratio was even higher. Averages for the isotopic ratios for a set of ten spectra were calculated, cor-

TABLE 3. Isotopic Ratios of Terrestrial Gd after Exposure to Thermal Neutrons

\begin{tabular}{|c|c|c|c|c|c|c|c|c|c|c|}
\hline Run No." & Bample & $\begin{array}{c}\text { Sample } \\
\text { Size, } \\
10^{-0} \mathrm{~g}\end{array}$ & $\begin{array}{c}\text { Sets of } 10 \\
\text { Ratios taken } \\
\text { with Multiplier } \\
\text { (MP) or Faraday } \\
\text { Cup (FC) }\end{array}$ & $\begin{array}{c}\text { Integrated } \\
\text { Neutron Flux } \\
\left(10^{15}\right. \\
\left.\text { Neutrong } / \mathrm{cm}^{2}\right)\end{array}$ & $\frac{\mathrm{Gd}^{168}}{\mathrm{Gd}^{160}}$ & $\frac{G^{167}}{G d^{160}}$ & $\frac{G^{156 b}}{G^{160}}$ & $\frac{G^{165}}{G^{180}}$ & $\frac{G^{165}}{G^{100}}$ & $\frac{\mathrm{Gd}^{152}}{\mathrm{Gd}^{160}}$ \\
\hline 56 (A) & $\mathrm{GdF}_{\mathbf{g}}$ & $\sim 2000$ & 8 (FC) & 59 & $\begin{array}{r}1.14325 \\
\pm .00006\end{array}$ & $\begin{array}{r}070628 \\
\pm 00009\end{array}$ & $\begin{array}{c}09361 \\
\ldots\end{array}$ & $\begin{array}{r}067323 \\
\pm .00007\end{array}$ & $\begin{array}{r}009949 \\
\pm \quad 00003\end{array}$ & $\begin{array}{c}000949^{\circ} \\
\pm 00005\end{array}$ \\
\hline 58 (A) & $\mathrm{GdF}_{\mathrm{j}}$ & $\sim 2000$ & 15 (FC) & 6.1 & $\begin{array}{r}1.13664 \\
\pm 00016\end{array}$ & $\begin{array}{r}0.71494 \\
\pm 00010\end{array}$ & $\begin{array}{c}0.9361 \\
\ldots\end{array}$ & $\begin{array}{r}067649 \\
\pm 00012\end{array}$ & $\begin{array}{r}009978 \\
\pm 00005\end{array}$ & $\begin{array}{c}0.00969^{\circ} \\
\pm 00005\end{array}$ \\
\hline $\begin{array}{c}54 \text { (A) } \\
\text { Terrestrial Gd }\end{array}$ & $\mathrm{GdF}_{\mathrm{z}}$ & $\sim 2000$ & 12 (FC) & 6.1 & $\begin{array}{c}1.1367 \\
\pm 0004 \\
1.13590 \\
\pm .00009\end{array}$ & $\begin{array}{c}0.7149 \\
\pm .0003 \\
0.71589 \\
\pm .00004\end{array}$ & $\begin{array}{c}09361 \\
\ldots \\
09361 \\
\ldots\end{array}$ & $\begin{array}{c}0.6765 \\
\pm 0004 \\
0.67692 \\
\pm 00009\end{array}$ & $\begin{array}{c}\cdots \\
0.09975 \\
\pm .00002\end{array}$ & $\begin{array}{c}\cdots \\
000928 \\
\pm .00002\end{array}$ \\
\hline
\end{tabular}

a (A) and (B) indicate that all sets that were averaged had standard deviations of the ratios Gd156 -159/Gd180 of less than 0.25 or $0.4 \%$, respectively.

b Fractionation correction normalized to $\mathrm{Gd}^{156} / \mathrm{Gd}^{180}=0.9361$.

- See section 2 under Interfering Ions. 
TABLE 4. Gd Isotopic Ratios of Meteorites Showing No Neutron-Capture Effects

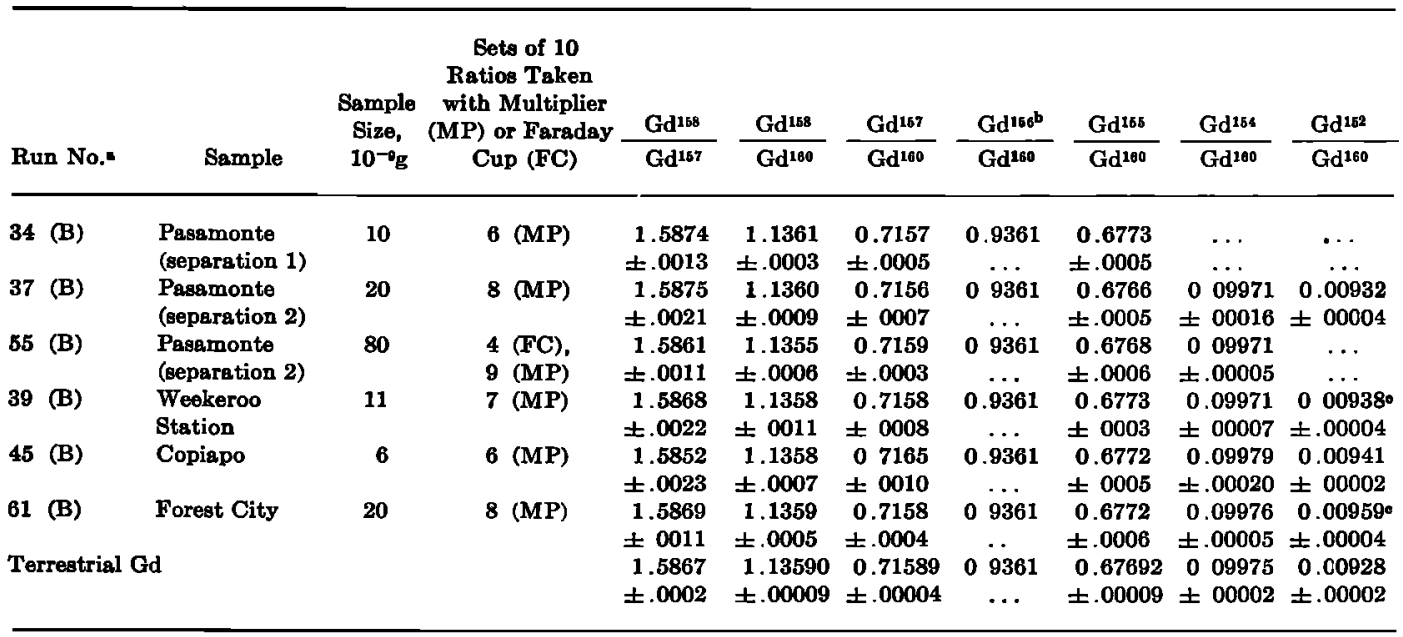

- (A) and (B) indicate that all sets that were averaged had atandard deviations of the ratiog Gd165-169/Gd160 of less than 0.25 or $0.4 \%$, respectively.

b Fractionation correction normalized to $\mathrm{Gd}^{160} / \mathrm{Gd}^{160}=\mathbf{0 . 9 3 6 1}$.

- See section 2 under Interfering Ions.

rected for the contribution of $\mathrm{O}^{\mathrm{in}}$ and $\mathrm{O}^{18}$, and normalized to $\mathrm{Gd}^{158} / \mathrm{Gd}^{100}=0.9361$ to correct for mass fractionation. At the beginning of an analysis, this ratio usually was about 0.940 (Faraday cup) and dropped to about 0.935 to- ward the end of the run. Tables 2-5 give the number of sets of ten spectra obtained for each run. One set of ten spectra including the zero readings on both sides of each peak could be taken within about 15 minutes. The ion beam

TABLE 5. Isotopic Ratios of Gd in the Norton County Achondrite

\begin{tabular}{|c|c|c|c|c|c|c|c|c|c|c|}
\hline Run No." & Separation & $\begin{array}{c}\text { Sample } \\
\text { Size, } \\
10^{-9} \mathrm{~g}\end{array}$ & $\begin{array}{c}\text { Seta of } 10 \\
\text { Ratios with } \\
\text { Multiplier (MP) } \\
\text { or Faraday Cup } \\
\text { (FC) }\end{array}$ & $\frac{G_{d^{158}}}{G_{d^{167}}}$ & $\frac{G^{168}}{G^{160}}$ & $\frac{\mathrm{Gd}^{157}}{\mathrm{Gd}^{160}}$ & $\frac{G_{d^{15} 6^{b}}}{G_{d^{160}}}$ & $\frac{\mathrm{Gd}^{156}}{\mathrm{Gd}^{180}}$ & $\frac{\mathrm{Gd}^{154}}{\mathrm{Gd}^{160}}$ & $\frac{\mathrm{Gd}^{162}}{\mathrm{Gd}^{180}}$ \\
\hline $48(B)$ & 1 & 12 & 9 (MP) & $\begin{array}{r}1.5907 \\
\pm .0019\end{array}$ & $\begin{array}{r}1.1364 \\
\pm 0007\end{array}$ & $\begin{array}{r}07144 \\
\pm 0007\end{array}$ & $\begin{array}{c}0.8361 \\
\ldots\end{array}$ & $\begin{array}{r}0.6766 \\
\pm 0005\end{array}$ & $\begin{array}{r}009865 \\
\pm 00015\end{array}$ & $\begin{array}{c}0.00944 \\
\pm .00004\end{array}$ \\
\hline 52 (B) & 1 & 12 & 10 (MP) & $\begin{array}{r}1.5914 \\
\pm .0014\end{array}$ & $\begin{array}{r}1.1374 \\
\pm .0007\end{array}$ & $\begin{array}{r}0.7147 \\
\pm 0004\end{array}$ & $\begin{array}{c}0.9361 \\
\ldots\end{array}$ & $\begin{array}{r}\mathbf{0 . 6 7 6 6} \\
\pm .0005\end{array}$ & $\ldots$ & $\ldots$ \\
\hline 59 (B) & 2 & 14 & $9(\mathrm{MP})$ & $\begin{array}{r}1.5909 \\
\pm 0014\end{array}$ & $\begin{array}{r}1.1367 \\
\pm 0006\end{array}$ & $\begin{array}{r}0.7145 \\
\pm .0005\end{array}$ & $\begin{array}{c}0.9361 \\
\ldots\end{array}$ & $\begin{array}{r}\mathbf{0 . 6 7 6 0} \\
\pm 0003\end{array}$ & $\begin{array}{r}0.09969 \\
\pm 00011\end{array}$ & $\begin{array}{r}0.00938^{\circ} \\
\pm .00005\end{array}$ \\
\hline $60(A)$ & 2 & 86 & 14 (FC) & $\begin{array}{r}1.5910 \\
\pm 0006\end{array}$ & $\begin{array}{r}1.13690 \\
\pm .00028\end{array}$ & $\begin{array}{r}0.71456 \\
\pm .00020\end{array}$ & $\begin{array}{c}09361 \\
\ldots\end{array}$ & $\begin{array}{r}067636 \\
\pm .00030\end{array}$ & $\begin{array}{ll} & \ldots \\
& \ldots\end{array}$ & $\ldots$ \\
\hline $60(A)$ & 2 & 86 & 28 (MP) & $\ldots$ & $\begin{array}{l}\ldots \\
\ldots\end{array}$ & $\ldots$ & $\begin{array}{c}0.9361 \\
\ldots\end{array}$ & $\ldots$ & $\begin{array}{r}009972 \\
\pm .00004\end{array}$ & $\begin{array}{c}000933^{\circ} \\
\pm .00001\end{array}$ \\
\hline \multicolumn{4}{|c|}{ Average for separation 1 (B) } & $\begin{array}{r}1.5910 \\
\pm .0010\end{array}$ & $\begin{array}{r}1.13690 \\
\pm .00057\end{array}$ & $\begin{array}{r}0.71457 \\
\pm .00028\end{array}$ & $\begin{array}{c}09361 \\
\ldots\end{array}$ & $\begin{array}{r}0.67659 \\
\pm .00043\end{array}$ & $\begin{array}{r}009965 \\
\pm 00015\end{array}$ & $\begin{array}{c}0.00944^{\circ} \\
\pm 00004\end{array}$ \\
\hline \multicolumn{4}{|c|}{ Average for separation 2 (A) } & $\begin{array}{r}15911 \\
\pm 0006\end{array}$ & $\begin{array}{r}1.13687 \\
\pm .00025\end{array}$ & $\begin{array}{r}0.71454 \\
\pm .00019\end{array}$ & $\begin{array}{c}0.9361 \\
\ldots\end{array}$ & $\begin{array}{r}0.67631 \\
\pm 00030\end{array}$ & $\begin{array}{r}0.09971 \\
\pm 00004\end{array}$ & $\begin{array}{c}000933^{\circ} \\
\pm 00001\end{array}$ \\
\hline \multicolumn{4}{|c|}{ Terrestrial Gd } & $\begin{array}{r}1.5867 \\
\pm .0002\end{array}$ & $\begin{array}{r}1.13590 \\
\pm 00009\end{array}$ & $\begin{array}{r}0.71589 \\
\pm 00004\end{array}$ & $\begin{array}{c}09361 \\
\ldots\end{array}$ & $\begin{array}{r}0.67692 \\
\pm .00000\end{array}$ & $\begin{array}{r}0.09975 \\
\pm .00002\end{array}$ & $\begin{array}{r}0.00928 \\
\pm .00002\end{array}$ \\
\hline
\end{tabular}

- (A) and (B) indicato that all sets that were averaged had standard deviations of the ratios Gdi55-158/Gd150 of less than 0.25 or $0.4 \%$, respectively.

b Fractionation correction normalized to $\mathrm{Gd}^{150} / \mathrm{Gd}^{100}=0.9361$

- See section 2 under Interfering Ions. 
was always very stable and no change due to fractionation could be observed within one set of ten spectra.

Samples of less than $20 \mathrm{ng}$ Gd were analyzed using a 17-stage electron multiplier at a gain of $10^{4}$ and a $10^{10}-\mathrm{ohm}$ resistor. An intensity of eight volts for $\mathrm{Gd}^{160} \mathrm{O}^{18}$ ions could be obtained for several hours for a sample of $10^{-8}$ gram Gd. Samples of more than $20 \mathrm{ng}$ Gd could be analyzed using a Faraday cup collector with a $10^{\mathrm{u}}$ ohm resistor. Within one set of ten spectra, the signals of $\mathrm{Gd}^{154-180}$ were always recorded using the same amplifier range to eliminate scale-factor corrections.

The linearity of the $10^{11}-\mathrm{ohm}$ resistor was better than $0.02 \%$ for the ion currents obtained (see Figure 1 of Eugster et al. [1969]). To determine the linearity of the $10^{10}$-ohm resistor, we compared the Gd isotopic ratios obtained using this resistor with those using the $10^{11}$-ohm resistor. The agreement obtained was better than $0.03 \%$.

Figures $2 a$ and $2 b$ show typical beam profiles for masses 170 and 171. The distances $A B$
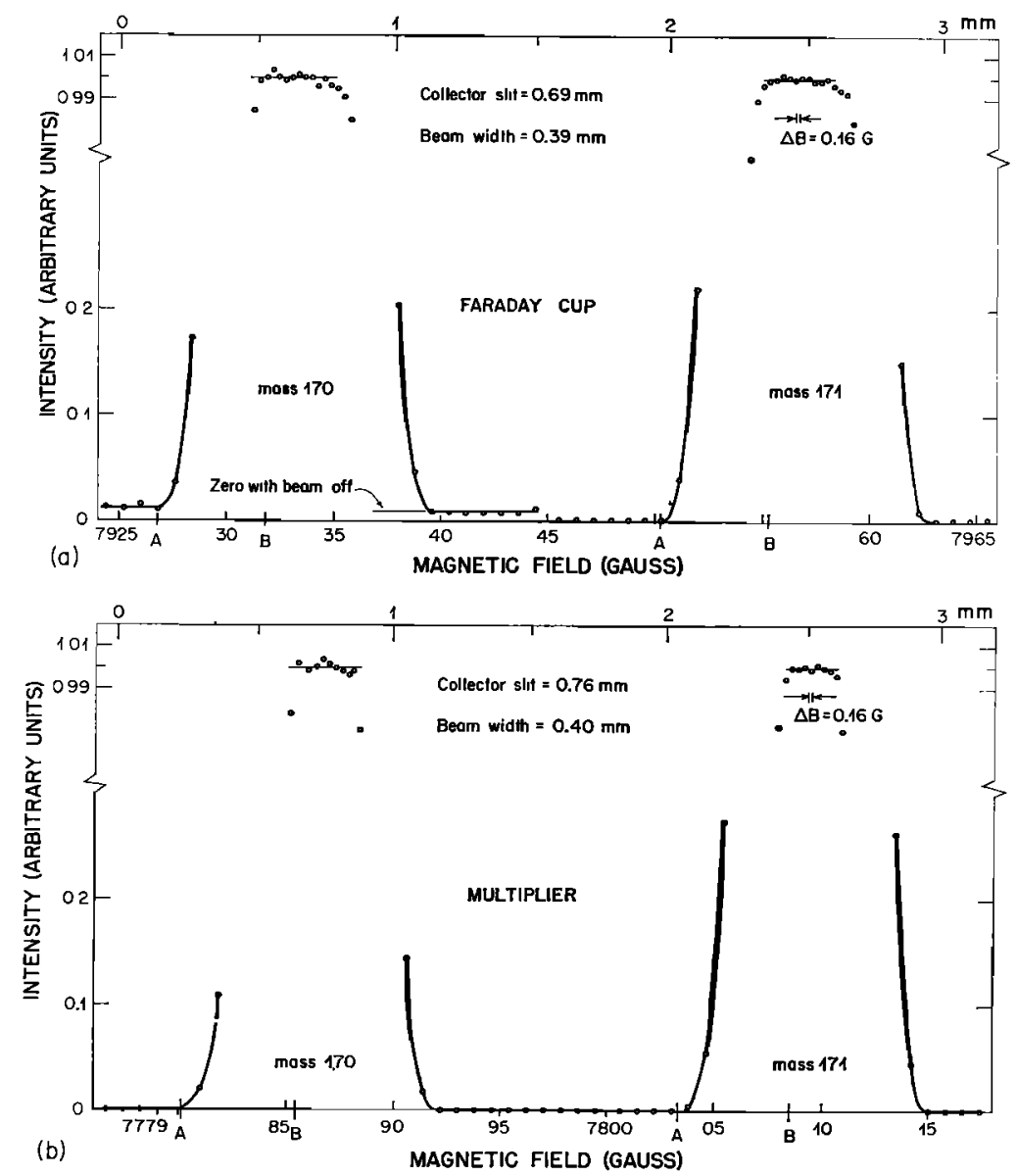

Fig. 2. Beam profiles for $\mathrm{Gd}$ at masses 170 and 171 for collector slit wider than beam width and beam intensities typical for meteorite analyses. The source slit was $0.23 \mathrm{~mm}$. Data points correspond to ion-beam currents at appropriate magnetic field values obtained by step scanning. At masses 170 and 171 the integrating times were $8 \mathrm{sec}$ and $2 \mathrm{sec}$, respectively, for each data point. The gauss equivalent in $\mathrm{mm}$ is given on the top axis. a) Beam profile obtained with Faraday cup. The signals of mass 170 and mass 171 correspond to ion currents of $10^{-13}$ amp and $6 \times 10^{-13} \mathrm{amp}$, respectively. b) Beam profile obtained with multiplier. The signals of mass 170 and mass 171 correspond to ion currents of $10^{-14} \mathrm{amp}$ and $6 \times 10^{-14}$ amp, respectively. 
correspond to the beam images at the respective collector slits of $0.39 \mathrm{~mm}$ (Faraday cup) and $0.40 \mathrm{~mm}$ (multiplier). The uncertainty $\Delta B=0.16 G$, corresponding to $\Delta B / B=$ $2 \times 10^{-5}$ [Wasserburg et al., 1969], of the magnetic field for locking in at a preset field value is negligible for a beam width that is about $0.3 \mathrm{~mm}$ narrower than the collector slit. At the intensities used for the sample measurements, the mass 170 and mass 171 peak tops are flat to better than $5 \times 10^{-3}$ and $2 \times 10^{-3}$, respectively.

3. Error calculation. For each set of ten ratios, mean values of the isotopic ratios $\mathrm{Gd}^{m}$ / $\mathrm{Gd}^{100}$ and standard deviations for the ratios were calculated. These standard deviations were used to define 'data categories' by means of which a given set of ratios could be accepted or rejected. Categories $B$ and $A$ data represent sets for which the standard deviations for the ratios $\mathrm{Gd}^{155-158} / \mathrm{Gd}^{100}$ were better than $0.4 \%$ and $0.25 \%$, respectively. Any set of data with standard deviations larger than those of category $B$ were rejected. Category $A$ data are tabulated in Tables 2-5 whenever possible. The isotopic ratios shown in Tables 2-5 are the averages of the means of all sets in the given category. The errors shown in Tables 2-5 are $2 \times\left[\Sigma_{i} \Delta_{i} / n\right.$ $(n-1)]^{1 / 2}$, where $n$ is the number of sets of ten ratios, and where $\Delta_{\mathfrak{r}}$ is the difference between the mean value of the ith set and the value given in the tables. Thus the errors given in this work correspond to $95 \%$ confidence limits.

\section{INTERFERING IoNS}

Although chemical separations were good, we explicitly investigated possible interferences by $\mathrm{BaCl}$ ions and by some rare-earth ions, rareearth oxide ions and rare-earth chloride ions.

1. $\mathrm{BaCl}$ interference. Since the sensitivity of $\mathrm{BaCl}$ ions for surface ionization is relatively high, even a small amount of $\mathrm{Ba}$ in the $\mathrm{Gd}$ fraction may cause interference problems with the GdO ions. The $\mathrm{Ba}$ in the Gd fraction, determined by isotopic dilution, was $10^{-10}$ gram Ba or less. Most of the $\mathrm{Ba}$ could be baked off by keeping the filament in the mass spectrometer for a few hours at a temperature that was slightly lower than the evaporation and ionization temperature of Gd. At the running temperature used for $\mathrm{Gd}$, the ratio of $\mathrm{BaCl}^{35} / \mathrm{Ba}$ was about 0.005 , and that of $\mathrm{Ba}^{139} / \mathrm{Gd}^{157} \mathrm{O}^{16}$ was usually $0.2-0.001$, depending on the original $\mathrm{Ba} / \mathrm{Gd}$ ratio and on the temperature history of the sample. In order to establish the extent of $\mathrm{BaCl}$ interference, we always checked $\mathrm{BaCl}$ during the data-taking period. The two possible mass positions for this purpose are mass 169 for $\mathrm{Ba}^{184} \mathrm{Cl}^{35}$ and mass 175 for $\mathrm{Ba}^{138} \mathrm{Cl}^{85}$. At mass $175, \mathrm{~Tb}^{160} \mathrm{O}^{10}$ and $\mathrm{Lu}^{175}$ may also appear. Since $\mathrm{Tb}$ and $\mathrm{Lu}$ are essentially mono-isotopic, it is not possible to exclude the presence of these elements completely. $\mathrm{Tb}$ is the neighbor of $\mathrm{Gd}$ on the heavier mass side, and a tailing of $\mathrm{Tb}$ during the rare earth separation could falsify a determination of $\mathrm{BaCl}$ based on this mass position. Therefore, we had to measure $\mathrm{Ba}^{134} \mathrm{Cl}^{25}$ at mass 169 and to verify the absence of $\mathrm{Eu}^{18} \mathrm{O}^{10}$ by checking $\mathrm{Eu}^{151} \mathrm{O}^{16}$ at mass 167 . By using mass 169 as a basis for the detection of $\mathrm{Ba}^{134} \mathrm{Cl}^{25}$, the following problem arises: The abundance of $\mathrm{Ba}^{128} \mathrm{Cl}^{35}$ is $\sim 30$ times higher than that of $\mathrm{Ba}^{124} \mathrm{Cl}^{35}$, so that an upper limit for a possible peak at mass 169 has to be magnified by a factor of 30 to apply the correction for $\mathrm{Ba}^{138} \mathrm{Cl}^{35}$ that interferes with the $\mathrm{Gd}^{16 \pi} \mathrm{O}^{18}$. This problem was solved by changing the $\mathrm{Ba}^{134} / \mathrm{Ba}^{138}$ ratio artificially to become about one by adding highly enriched $\mathrm{Ba}^{\text {Is }}$ to the sample after the chemical separation and to measure this $\mathrm{Ba}$ ratio before and after each set of $\mathrm{Gd}$ spectra. The amount of enriched $\mathrm{Ba}^{\mathrm{is}}$ added to the sample was always less than $10^{-10}$ gram. The ratio of $\mathrm{Gd}^{m} / \mathrm{Ba}^{134}$ in the $\mathrm{Ba}^{1 \mathrm{ss}}$ spike was checked by adding enriched $\mathrm{Gd}^{105}$ and found to be less than $2 \times 10^{-8}$ for each $\mathrm{Gd}$ isotope $m$ and thus could not change the composition of $\mathrm{Gd}$ in the sample. In all the runs through run 48 , the samples were not spiked with $\mathrm{Ba}^{134}$, and therefore the uncertainty in the abundance of $\mathrm{Gd}^{15 \pi}$ that is most affected by a $\mathrm{BaCl}$ contribution is higher than for the runs performed later. For the runs $34,37,39,45$, and 48 , the $\mathrm{BaCl}$ corrections applied were between $0.04 \%$ and $0.125 \%$, and a $100 \%$ error for each correction was added quadratically to the statistical errors shown in Tables 2-5. For all other runs the $\mathrm{BaCl}$ corrections could be proven to be less than $0.01 \%$ and were thus negligible. It may be added that $\mathrm{BaF} / \mathrm{BaCl}$ was $\sim 10$, so that the problem would not have been solved by measuring the $\mathrm{Gd}$ ions with which the $\mathrm{BaF}$ ions interfere.

2. Interference by other rare earths. The 
following rare-earth ions, rare-earth oxide ions or rare-earth chloride ions could interfere with GdO ions and were checked repeatedly during each run: $\mathrm{Er}, \mathrm{Lu}, \mathrm{Hf}, \mathrm{DyO}$, and $\mathrm{CeCl}$ with the $\mathrm{GdO}$ masses $170-176$ were less than $0.001 \%$ for each isotope, and with mass 168 were less than $0.02 \%$. The presence of $\mathrm{Yb}$ ions could not be checked, the isotopes of this element occupying exactly the same mass positions as $\mathrm{GdO}^{16}$. However, the chemical separation of $\mathrm{Yb}$ from Gd was even better than that of Dy and $\mathrm{Er}$, for which no traces were found in the samples, so that the abundance of $\mathrm{Yb}$ in the sample must have been extremely low. A contamination of $\mathrm{Gd}$ by $0.1 \%$ of $\mathrm{Yb}$ relative to $\mathrm{Gd}$ would increase the ratio $\mathrm{Gd}^{157} / \mathrm{Gd}^{100}$ by $\sim 0.01 \%$ and that of $\mathrm{Gd}^{158} / \mathrm{Gd}^{100}$ by $\sim 0.05 \%$ if the isotopic ratios are normalized to a constant $\mathrm{Gd}^{158} / \mathrm{Gd}^{180}$ ratio. Hence anomalies resembling those for neutron capture cannot be introduced by an $\mathrm{Yb}$ contribution. The same is true for an addition of $\mathrm{LaCl}$ to masses 174 and 176 and $\mathrm{CeO}_{2}$ to masses 172 and 174. Besides, the presence of $\mathrm{LaCl}$ and $\mathrm{CeO}_{2}$ ions was unlikely since $\mathrm{La}$ and $\mathrm{Ce}$ ions were not detected. $\mathrm{LaO}_{2}$ would interfere with $\mathrm{Gd}^{155} \mathrm{O}$ and $\mathrm{PrO}_{2}$ with $\mathrm{Gd}^{150} \mathrm{O}$. However, we never observed a systematic variation of the ratios $\mathrm{Gd}^{158-158} / \mathrm{Gd}^{180}$ although we changed the $\mathrm{GdO}$ ion current during the course of the analyses by a factor of up to 100 corresponding to a variation of the filament temperature of about $200^{\circ} \mathrm{C}$. We may therefore assume that the contribution of the compounds of the other rare earths to the masses of $\mathrm{Gd}^{105-100} \mathrm{O}$ that will be used for the discussion of neutron capture effects was negligibly small.

For most of the samples, we observed a systematic enhancement of the abundances of masses $168\left(\mathrm{Gd}^{125} \mathrm{O}\right)$ and $170\left(\mathrm{Gd}^{25} \mathrm{O}\right)$ indicating that an $\mathrm{Sm}$ contribution was present, caused by the blank of the second ion-exchange column, not by incomplete chemical separation. Although both $\mathrm{Gd}^{154} / \mathrm{Gd}^{100}$ and $\mathrm{Gd}^{152} / \mathrm{Gd}^{100}$ are of no significance for the discussion of neutron-capture effects (see section 2 under Discussion), we corrected for $\mathrm{Sm}$ in order to ensure that the enrichments of $\mathrm{Gd}^{154}$ and $\mathrm{Gd}^{100}$ are compatible with a $\mathrm{Sm}$ contribution. $\mathrm{Sm}$ isotopes that did not interfere with these two $\mathrm{Gd}$ isotopes were detectable at the beginning of the runs. However, at the temperature at which data were taken, the ratios $\mathrm{Sm} / \mathrm{Gd}^{100}$ dropped below $2 \times 10^{-5}$.
Because of an enhanced background due to deflected ions in the region of the lower SmO masses these small peaks became undetectable. We therefore corrected the measured ratio $(154 / 160)_{\text {meas }}$ based on the measured ratio $(152 / 160)_{\text {meas. }}$ Equation 1 pays regard to the fact that for samples with neutron-capture effects $\mathrm{Gd}^{150}$ is enriched by neutron capture of $\mathrm{Eu}^{1 \mathrm{11}}$. Furthermore, a mass-fractionation correction for $(152 / 160)_{\text {moa }}$ has to be applied for samples with neutron-capture effects because the mass fractionation calculated by using a constant ratio $\left(\mathrm{Gd}^{150} / \mathrm{Gd}^{100}\right)=0.9361$ is not the true mass fractionation. The ratio $\mathrm{Gd}^{25 /} /$ $\mathrm{Gd}^{100}$ corrected for the $\mathrm{Sm}$ contribution was calculated according to equation 1 :

$$
\begin{aligned}
\left(\mathrm{Gd}^{154} / \mathrm{Gd}^{160}\right)_{\mathrm{corr}}=(154 / 160)_{\text {meas }} \\
-\left\{(152 / 160)_{\text {meas }}\right. \\
\times\left[1+2\left(\mathrm{Gd}^{155} / \mathrm{Gd}^{156}\right)_{\text {terr }}(\varphi t) \sigma^{155}\right] \\
-\left(\mathrm{Gd}^{152} / \mathrm{Gd}^{160}\right)_{\text {terr }} \\
\left.-\left(\mathrm{Eu}^{151} / \mathrm{Gd}^{160}\right)_{\text {sample }}(\varphi t) \sigma^{155}\right\} \\
\quad \times\left(\mathrm{Sm}^{154} / \mathrm{Sm}^{152}\right)_{\text {terr }}
\end{aligned}
$$

Here the terrestrial Gd isotopic ratios are as given in Table 2 and $\left(\mathrm{Sm}^{154} / \mathrm{Sm}^{252}\right)_{\text {terr }}=0.845$ [Collins et al., 1957]. $(\varphi t)$ is the neutron flux in the sample calculated using Equation 9 and $\sigma^{1 \times 5}=62,500$ barns (see section 2 under Discussion). For $\sigma^{10}$, the thermal neutron-capture cross section of $\mathrm{Eu}^{10 \mathrm{in}}$ for the production of $\mathrm{Gd}^{100}$, we used the value of 4000 barns.

The Sm correction of all analyses of reagent Gd was less than $0.01 \%$ for $\mathrm{Gd}^{154}$ and less than $0.1 \%$ for $\mathrm{Gd}^{\mathrm{was}}$, and thus negligible. This could be established because relatively high ion beams were obtained for the relatively big amounts of reagent sample loaded on the filament.

The ratios $\mathrm{Gd}^{202} / \mathrm{Gd}^{100}$ given in Tables 2-5 are always the values uncorrected for any possible interferences, whereas those of $\mathrm{Gd}^{154} / \mathrm{Gd}^{1200}$ are always corrected for $\mathrm{Sm}^{164}$ based on the measured $\mathrm{Gd}^{150} / \mathrm{Gd}^{100}$ using equation 1 . The $\mathrm{Sm}$ correction to $\mathrm{Gd}^{154}$ was always less than $0.3 \%$. The isotopes $\mathrm{Gd}^{150-100}$, which are important for neutron capture effects, are not affected by a possible $\mathrm{Sm}$ contribution.

3. Hydrocarbons. By closing the collector slit from the regular width (see Figures $2 a$ and 
2b) to $0.25 \mathrm{~mm}$, hydrocarbon peaks could be partially resolved from the GdO peaks. No hydrocarbons (less than $0.01 \%$ for each Gd isotope) could be detected in the GdO region at the time that measurements were being made.

4. Oxygen correction. In all runs GdO ions were measured. In order to obtain the isotopic ratios of the Gd ions, small corrections for the compounds of the two neighboring $\mathrm{Gd}$ isotopes on the lower mass side with $\mathrm{O}^{17}$ and $\mathrm{O}^{28}$ have to be applied. As described earlier, the averages of the ratios of the ion beam readings at the masses where $\mathrm{GdO}^{1 \mathrm{\theta}}$ occurred $(168 / 176,170 /$ $176,171 / 176,172 / 176,173 / 176$ and $174 / 176$ ) were calculated for a set of ten spectra. Thereupon, corrections for the contributions of $\mathrm{GdO}^{17}$ and $\mathrm{GdO}^{18}$ to the above masses were calculated according to equations 2-7:

$$
\begin{aligned}
& (168 / 176)_{\text {oorr }}=1.00232 \times(168 / 176)_{\mathrm{meas}} \\
& (170 / 176)_{\mathrm{oorr}}=1.00213 \times(170 / 176)_{\mathrm{meas}} \\
& (171 / 176)_{\mathrm{oorr}}=1.00226 \times(171 / 176)_{\mathrm{mess}} \\
& (172 / 176)_{\mathrm{oorr}}=1.00183 \times(172 / 176)_{\mathrm{meas}} \\
& (173 / 176)_{\mathrm{oorr}}=0.99990 \times(173 / 176)_{\mathrm{meas}} \\
& (174 / 176)_{\mathrm{oorr}}=1.00040 \times(174 / 176)_{\mathrm{meas}}
\end{aligned}
$$

Here the ratios indicated by the subscript 'meas' are the measured ratios (uncorrected for fractionation), whereas those indicated by 'corr' are the ratios corrected for the contributions of the compounds of $\mathrm{Gd}$ with $\mathrm{O}^{17}$ and $\mathrm{O}^{18}$. Equations 2-7 yield the ratios of the Gd isotopes uncorrected for mass discrimination. All data presented in this work relate to $\mathrm{Gd}$ after correction for $\mathrm{O}^{17}$ and $\mathrm{O}^{\mathrm{x}}$.

For the ratios $0^{18} / 0^{10}$ and $0^{17} / 0^{10}$, we used the values as given by Nier [1950], who quotes errors of $0.1 \%$ and $0.7 \%$, respectively. In addition to these statistical errors, there might be systematic errors of the oxygen isotopic ratios caused by a mass fractionation that we estimate to be less than $1 \%$ per mass unit. Therefore we assume the values used for the isotopic ratios of oxygen to be correct within $\pm 2 \%$. Using values of the isotopic ratios $\mathrm{O}^{18}$ / $\mathrm{O}^{10}$ and $\mathrm{O}^{17} / \mathrm{O}^{10}$ differing by $2 \%$, the correction factors in equations 2-7 change by less than five parts in $10^{5}$, which is negligible compared to our experimental uncertainty.
Furthermore, any systematic errors in the oxygen corrections would not affect a comparison between different samples with small anomalies.

After the $\mathrm{Gd}$ isotopic ratios of a set of ten spectra were corrected as outlined above, the isotopic ratios were then corrected for mass fractionation by normalization to $\mathrm{Gd}^{150} / \mathrm{Gd}^{180}=$ 0.9361 . This value corresponds to the typical (to within $0.5 \%$ ) ratios $\mathrm{Gd}^{158} / \mathrm{Gd}^{100}$ (not corrected for mass fractionation), which were measured on reagent Gd using the Faraday cup. It was chosen as basis of the mass fractionation correction in order to keep the correction as small as possible. This is distinct from the literature value of Collins et al. [1957].

\section{Restuts}

1. Terrestrial gadolinium. In Table 2 the isotopic ratios obtained for terrestrial $\mathrm{Gd}$ are compiled. The contributions of $\mathrm{BaCl}$ and $\mathrm{Sm}$ were less than $0.01 \%$ for all runs in Table 2 . The mass fractionation correction was made by normalizing the $\mathrm{Gd}^{150} / \mathrm{Gd}^{100}=0.9361$. The different measurements agree within the statisitical errors, and no systematic differences were found between data obtained using the multiplier (MP) and those obtained using the Faraday cup (FC).

The excellent reproducibility of the analyses tabulated in Table 2 shows that the calculated statistical error provides a realistic estimate of the over-all precision for a given mass spectrometric analysis. Further, these indicate that isotopic variations of $0.1 \%$ in the $\mathrm{Gd}^{250-150} / \mathrm{Gd}^{180}$ should be detected even for small (less than $10^{-7}$-gram samples).

Table 2 also gives values for the terrestrial Gd isotopic ratios as determined by Collins et al. [1957]. Our results agree reasonably well with the data to within the precision that they report. Although there undoubtedly is a small systematic error due to mass discrimination in both the present and the literature data, it is reasonable to use the abundance data reported in the present work for Gd over that of previous workers because of the higher precision of the new data. The per cent abundances of terrestrial Gd found in our work for $\mathrm{Gd}^{100}, \mathrm{Gd}^{16 s}$, $\mathrm{Gd}^{165}, \mathrm{Gd}^{150}, \mathrm{Gd}^{155}, \mathrm{Gd}^{154}$, and $\mathrm{Gd}^{150}$ are $21.863 \pm$ $0.002,24.835 \pm 0.004,15.652 \pm 0.002,20.466 \pm$ $0.002,14.800 \pm 0.003,2.1809 \pm 0.0006,0.2029$ 
\pm 0.0005 , respectively. It should be emphasized that these values are relative abundances. The errors given do not include the uncertainty due to the unknown mass fractionation.

2. Irradiation experiment. We have analyzed irradiated $\mathrm{Gd}$ samples in order to confirm the expected sensitivity for detecting small neutron-capture effects of $\mathrm{Gd}^{157}$ and $\mathrm{Gd}^{155}$. Thin layers of $\mathrm{GdF}_{\mathrm{a}}$ were vaporized in vacuum onto high-purity $\mathrm{Al}$ foils. To prevent self-shielding effects the thickness was adjusted to about $10^{-4}$ gram $\mathrm{GdF}_{\mathrm{a}} / \mathrm{cm}^{2}$. Two samples were exposed to a well-thermalized neutron flux in the Brookhaven Medical Reactor together with two Au monitors located above and below the Gd sample. One exposure was $10 \mathrm{~min}$, the other was $100 \mathrm{~min}$. A sample of Cd-covered Au was exposed separately to correct for epithermal contributions to the observed $\mathrm{Au}^{109}$ activity. After the irradiation the thermal neutron fluxes were determined, based on the $\mathrm{Au}^{109} \gamma$ activity of the monitors and are given in Table 3. The Gd was removed from the Al foil by washing off with $\sim 0.5 \mathrm{~N} \mathrm{HCl}$. The two flux monitors within each sample gave the same flux to within $5 \%$. The measured integrated fluxes for the irradiations agreed with the flux values given by the reactor operators to better than $10 \%$.

The results obtained are shown in Table 3 . All data are normalized to the same ratio $\mathrm{Gd}^{158}$ / $\mathrm{Gd}^{100}=0.9361$ as the terrestrial samples (i.e., an effective discrimination is calculated assuming this ratio). A normalization procedure based on $\mathrm{Gd}^{154} / \mathrm{Gd}^{100}$ is more suited for the discussion of neutron-capture anomalies since $\mathrm{Gd}^{154}$ and $\mathrm{Gd}^{190}$ are not affected. However, the precision of this ratio is in most cases considerably lower than for $\mathrm{Gd}^{155-159} / \mathrm{Gd}^{100}$. We have made allowance for the fact that the discrimination calculated by using $\mathrm{Gd}^{150} / \mathrm{Gd}^{180}=0.9361$ is not the true discrimination in samples that have been changed by neutron capture.

This can be taken into consideration in a plot of $\mathrm{Gd}^{158} / \mathrm{Gd}^{100}$ versus $\mathrm{Gd}^{150} / \mathrm{Gd}^{100}$ (both normalized to $\mathrm{Gd}^{150} / \mathrm{Gd}^{180}=0.9361$ ). To first order, the correlation curve of these ratios is a line with the slope
For $\sigma^{155} / \sigma^{152}$ we used the value of 0.2386 [M $\phi$ ller et al., 1960].

Figure 3 shows the correlation line calculated according to equation 8 and the data points for the irradiated samples. For changes by neutron capture of $\mathrm{Gd}^{157} / \mathrm{Gd}^{160}$ of $2 \%$ or less, the slope of the correlation line changes by less than $0.13 \%$. The experimental data agree exactly with the calculated line. If we had normalized the $\mathrm{Gd}$ isotopic ratios to a constant ratio $\mathrm{Gd}^{154} /$ $\mathrm{Gd}^{180}$, the slope of the corresponding correlation line would be -1 .

The cross-section ratio and hence the correlation line is very insensitive to neutron energy in the thermal region.

Note that the slope of the correlation line depends only on $\sigma^{150} / \sigma^{157}$ and not on the integrated neutron flux. The integrated flux determines the position of a given point along the correlation line.

Figure 4 shows the correlation of $\mathrm{Gd}^{150} / \mathrm{Gd}^{180}$ versus $\mathrm{Gd}^{157} / \mathrm{Gd}^{100}$, normalized to $\mathrm{Gd}^{158} / \mathrm{Gd}^{100}=$ 0.9361 . The correlation line has a slope of 0.3797 that changes by less than $0.3 \%$ for variations of the ratio $\mathrm{Gd}^{157} / \mathrm{Gd}^{180}$ of $2 \%$ or less.

Although the capture cross section is not strictly proportional to $1 / V$, neutron capture of $\mathrm{Gd}^{157}$ can be described by an average value of $\sigma V=4.75 \times 10^{-14} \mathrm{~cm}^{3} / \mathrm{sec}$ (see section 1 under Discussion). Using this and the thermal neutron density calculated from the measured $\mathrm{Au}^{109} \mathrm{ac}-$ tivity, the expected percentage changes in the corrected $\mathrm{Gd}^{158} / \mathrm{Gd}^{157}$ ratios would be $2.1 \%$ and $0.22 \%$ for the long and short irradiations, respectively. The corresponding measured changes of $(2.02 \pm 0.03) \%$ and $(0.20 \pm 0.03) \%$ are in excellent agreement with the above predictions.

The analyses of the irradiated samples have thus demonstrated that $0.1 \%$ isotopic variations due to neutron capture can be readily detected. This confirms the sensitivity predicted from the precision of the measurements on terrestrial samples. The irradiation experiments also indicate that reliable neutron fluxes can be calculated from $\mathrm{Gd}$ isotopic measurements using

$$
\frac{d(158 / 160)_{\text {norm }}}{d(157 / 160)_{\text {norm }}}=-\frac{\left[1-0.5\left(\sigma^{155} / \sigma^{157}\right)(155 / 156)_{\text {terr }}(158 / 157)_{\text {terr }}\right]}{\left[1+0.75\left(\sigma^{155} / \sigma^{157}\right)(155 / 156)_{\text {terr }}\right]}=-0.764
$$




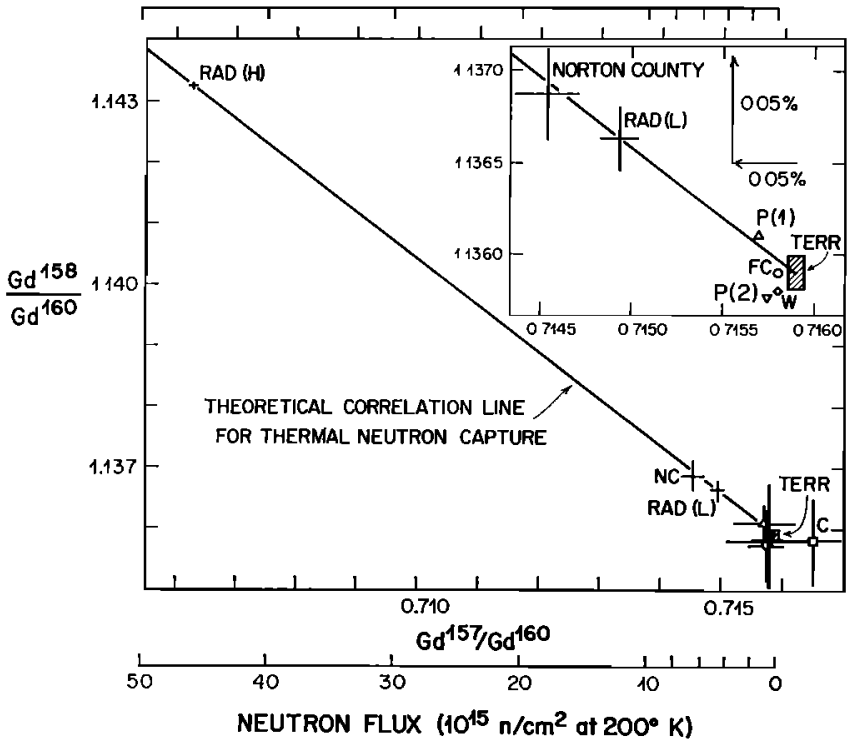

Fig. 3. $\mathrm{Gd}^{158} / \mathrm{Gd}^{160}$ versus $\mathrm{Gd}^{157} / \mathrm{Gd}^{100}$ correlation diagram. Changes of the isotopic ratios of $\mathbf{0 . 0 5 \%}$ are indicated by the two arrows shown. The scale for the neutron flux corresponding to the $\mathrm{Gd}^{157} / \mathrm{Gd}^{100}$ values is calculated for $\sigma^{157}\left(200^{\circ} \mathrm{K}\right)=262,000$ barns. For $\sigma^{157}\left(293^{\circ} \mathrm{K}\right)=$ 215,600 barns and for $\sigma^{167}\left(373^{\circ} \mathrm{K}\right)=179,200$ barns, the scale for the neutron flux has to

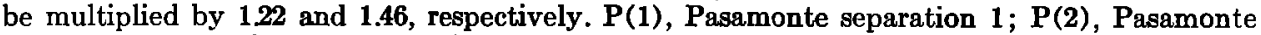
separation 2; W, Weekeroo Station; C, Copiapo; FC, Forest City; NC, Norton County; RAD(H), highly irradiated terrestrial Gd; RAD(L), low-irradiated terrestrial Gd; TERR, terrestrial Gd. The squares, triangles, etc. represent corresponding points on the main and inset figure. For better clarity, the error bars for the meteorites showing no neutroncapture effects and the point for Copiapo are not shown in the inset figure.

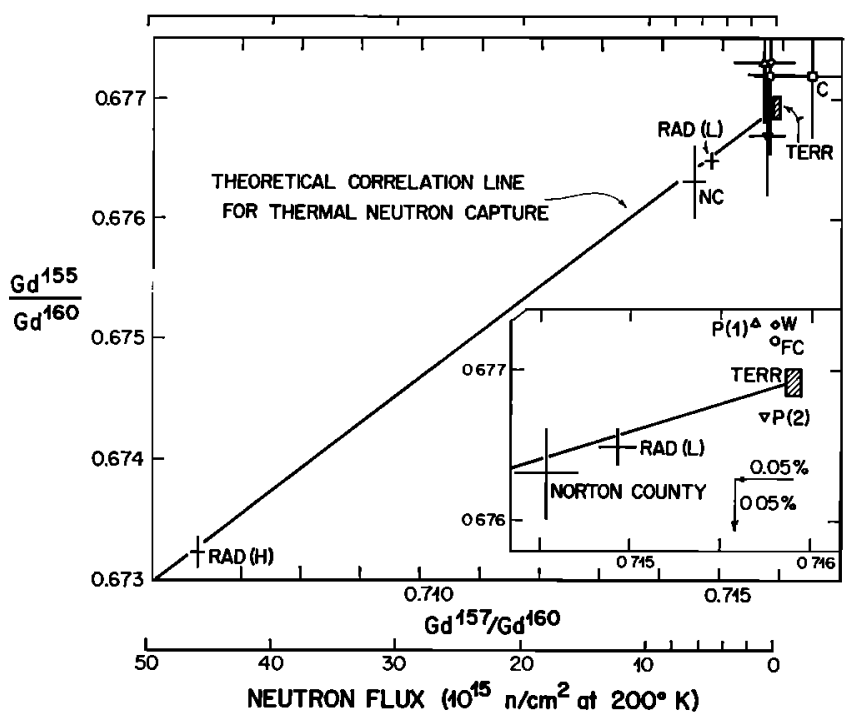

Fig. 4. $\mathrm{Gd}^{155} / \mathrm{Gd}^{100}$ versus $\mathrm{Gd}^{157} / \mathrm{Gd}^{100}$ correlation diagram. See caption of Figure 3 . 
the available laboratory neutron cross section data.

3. Gd concentrations. For samples for which the Gd concentrations were not known, a small aliquot of the Gd sample was spiked after the chemical separation with enriched $\mathrm{Gd}^{155}$ and analyzed. Since the $\mathrm{Gd}$ yield of the first ionexchange column used was more than $99 \%$ and that of the second one about $96 \%$ (see Figure 1 ), we estimate our Gd concentrations given in Table 1 to be correct within about ten per cent.

4. Meteorites showing no $G d$ anomalies. Table 4 gives the data for meteorites showing no neutron capture anomalies. Within the limits of experimental errors, the results for each run agree with the results for terrestrial Gd. The quality of the data differs considerably for different runs, depending mainly on the size of the sample analyzed. A small $\mathrm{BaCl}$ correction had to be applied for the runs of very small samples (runs $34,37,39$, and 45 ) and a $100 \%$ error for each correction was added quadratically to the statistical errors. Therefore, these data are of somewhat lower quality than those for which the $\mathrm{BaCl}$ correction was negligibly small.

For Pasamonte, two different chemical separations and three different mass-spectrometer runs of widely varying sample sizes were performed. The reproducibilities of the ratios $\mathrm{Gd}^{135-158} / \mathrm{Gd}^{180}$ for the different chemical separations and also for the different runs of the same chemical separation are well within the experimental errors of less than $0.1 \%$. The most precise analysis of Pasamonte (run 55) is about of the same quality as that of Forest City. For both runs the $\mathrm{BaCl}$ correction was negligible, and the precision is about $0.05 \%$ for the ratios of the abundant $\mathrm{Gd}$ isotopes.

The samples of the silicate inclusions of the two iron meteorites, Copiapo and Weekeroo Station, were very small. The Gd isotopic composition of Weekeroo Station agrees well with that of terrestrial $\mathrm{Gd}$ although the error limits are about $0.1 \%$. Copiapo, for which a sample of only $6 \times 10^{-9}$ gram Gd was analyzed and for which the highest $\mathrm{BaCl}$ correction had to be applied, shows the least precise value of the ratio $\mathrm{Gd}^{158} / \mathrm{Gd}^{100}$. However, since no neutroncapture anomalies are evident within experimental errors, we considered it unnecessary to repeat the analysis. The data points of the meteorites showing no neutron-capture anom- alies are shown in Figures 3 and 4. The ratios $\mathrm{Gd}^{167} / \mathrm{Gd}^{180}$ for Pasamonte, Weekeroo Station, and Forest City lie within $0.04 \%$ of the data point for terrestrial $\mathrm{Gd}$.

5. The Norton County achondrite. Table 5 gives the results for the Norton County achondrite. We carried out two different chemical separations. For separation 2, we processed four aliquots of $100-\mathrm{mg}$ solid sample through the first ion-exchange column. Then we combined the four rare-earth fractions for the separation of $\mathrm{Gd}$ using the second ion-exchange column. For each separation, two mass-spectrometer runs were performed. Inspection of the data shows that for each run significant anomalies are present compared to terrestrial Gd. The results for all four runs agree within the experimental errors. For run 48 , a $\mathrm{BaCl}$ correction of $0.1 \%$ and less had to be applied; for all other runs, the $\mathrm{BaCl}$ contribution was negligibly small. Samples of $\sim 13 \times 10^{-8}$ gram Gd were analyzed using the multiplier with statistical error limits of about $0.07 \%$ for the ratios $\mathrm{Gd}^{155-159} / \mathrm{Gd}^{100}$. The data for the sample of $86 \times$ $10^{-9}$ gram Gd were obtained using the Faraday cup, and the experimental errors are two to three times smaller than those of the three other runs. The data shown for the average of separation 2 were obtained by calculating average values for those data sets from runs 59 and 60 whose standard deviations were less than $0.25 \%$ for the ratios $\mathrm{Gd}^{155-158} / \mathrm{Gd}^{100}$ and less than $0.5 \%$ for the ratio $\mathrm{Gd}^{154} / \mathrm{Gd}^{180}$. The average values for separation 1 agree almost exactly with those for separation 2. The more precise data are shown in Figures 3 and 4 . The agreement with the neutron-capture correlation lines is very good, and we can conclude that the anomalies found in Norton County are caused by a thermal neutron flux.

\section{Discussion}

1. Irradiation models. As indicated in the Introduction, the conclusions drawn from the Gd isotopic measurements depend on the irradiation model adopted. We discuss three simple types of irradiations:

a. In-situ irradiation of the meteorites at some time subsequent to their formation, e.g., by galactic cosmic rays or solar flare neutrons.

b. A uniform primordial irradiation of both 
meteoritic and terrestrial matter at a time when they were sufficiently dispersed so that all the material was irradiated. For both $a$ and $b$ identical values for integrated neutron fluxes are calculated. However, for $b$ the calculated flux is the difference in the integrated fluxes experienced by terrestrial and meteoritic material, whereas for $a$ the calculated value is the magnitude of the flux because we assume that terrestrial material has not been irradiated.

c. An intense primordial irradiation of only a fraction of the solar system material followed by mixing of the irradiated and unirradiated fractions (e.g., as suggested by Fowler et al. [1962]). $\mathrm{Gd}^{157}$ and $\mathrm{Gd}^{158}$ are assumed to be totally depleted in the irradiated material. In this case, $\mathrm{Gd}$ isotopic variations reflect variations in the mixing ratio of irradiated and unirradiated material rather than flux variations. Models $b$ and $c$ are extremes. A continuum of intermediate models exists.

2. Effective capture cross sections of $G d$. The large thermal cross sections of $\mathrm{Gd}^{155}$ and $\mathrm{Gd}^{157}$ are due to low-energy resonances; how- constant at $4.1 \pm 0.1$ over this temperature range. Because of the approximate constancy of $\langle\sigma V\rangle$, the neutron density can be determined relatively unambiguously by measurement of $\mathrm{Gd}^{157}$ isotopic variations, whereas the calculation of an integrated thermal neutron flux requires the assumption of a temperature. However, deviations of the actual energy spectrum from a Maxwell-Boltzmann distribution are possible for near-surface samples and for samples that are comparatively strong neutron absorbers. We have thus assumed a temperature of $200^{\circ} \mathrm{K}$ and calculated fluxes and flux limits. The corresponding effective capture cross section for $\mathrm{Gd}^{157}$ of $262 \mathrm{~kb}$ will be used in all the following calculations.

The isotopic ratio $\mathrm{Gd}^{158} / \mathrm{Gd}^{157}$ is more sensitive to a neutron flux than are the other ratios measured. We therefore included these ratios in Tables 4 and 5 and calculated the experimental errors by adding quadratically the errors of the measured $\mathrm{Gd}^{158} / \mathrm{Gd}^{190}$ and $\mathrm{Gd}^{159} / \mathrm{Gd}^{100}$. To the first order the integrated neutron fluxes can then be calculated

$$
\begin{aligned}
(\phi t) & \cong \frac{\left(\mathrm{Gd}^{158} / \mathrm{Gd}^{157}\right)_{\text {meas }}-\left(\mathrm{Gd}^{158} / \mathrm{Gd}^{157}\right)_{\mathrm{terr}}}{\sigma^{157}\left[1+\left(\mathrm{Gd}^{158} / \mathrm{Gd}^{157}\right)_{\text {terr }}\right]+\frac{1}{4} \sigma^{155}\left(\mathrm{Gd}^{158} / \mathrm{Gd}^{157}\right)_{\mathrm{terr}}\left(\mathrm{Gd}^{155} / \mathrm{Gd}^{156}\right)_{\text {terr }}} \\
& =1.44 \times 10^{18}\left[\left(\mathrm{Gd}^{158} / \mathrm{Gd}^{157}\right)_{\text {meas }}-\left(\mathrm{Gd}^{158} / \mathrm{Gd}^{157}\right)_{\text {terr }}\right] n / \mathrm{cm}^{2}
\end{aligned}
$$

ever, the resonance energies $(0.0268$ and 0.0314 $\mathrm{ev}$, respectively) are sufficiently low that the $1 / V$ behavior dominates the energy dependence of the cross section. Thus, below about $0.04 \mathrm{ev}$, the cross sections are approximately $1 / V$. We assume that the neutrons with energies below about $0.1 \mathrm{ev}$ undergo a sufficient number of collisions to attain a Maxwell-Boltzmann energy distribution. Thus, because $0.04 \mathrm{ev}$ is higher than the $\mathrm{kT}$ values of interest, the value of $\sigma \mathrm{V}$ averaged over a thermal distribution $\langle\sigma V\rangle$ should not depend strongly on the temperature. Calculations of $\langle\sigma V\rangle$ using the single level BreitWigner resonance parameters of $M ø l l e r$ et al. [1960] showed that $\langle\sigma V\rangle=4.75 \times 10^{-14}$ $\mathrm{cm}^{3} / \mathrm{sec}$ to within $\pm 5 \%$ between $100^{\circ} \mathrm{K}$ and $393^{\circ} \mathrm{K}$ for $\mathrm{Gd}^{15 \pi}$. However, this value is about $20 \%$ lower than $\sigma V$ evaluated at $V=$ $2200 \mathrm{~m} / \mathrm{sec}$, reflecting the fact that the cross section is not strictly proportional to $1 / V$. The ratio of $\left\langle\sigma^{157} V\right\rangle$ to $\left\langle\sigma^{155} V\right\rangle$ is also approximately
The second term in the denominator stems from the normalization of the measurements to $\mathrm{Gd}^{158}$ / $\mathrm{Gd}^{100}=0.9361$. This first-order approximation introduces an error of less than $1 \%$ in the calculated flux for variations in $\mathrm{Gd}^{158} / \mathrm{Gd}^{157}$ of $1.3 \%$ or less.

3. Neutron fluxes due to in-situ irradiations. The data in Table 4 show that any differences in the $\mathrm{Gd}^{158} / \mathrm{Gd}^{157}$ ratio are less than about 0.002 which, from equation 9 , implies an upper limit on the in-situ integrated thermal neutron flux of $3 \times 10^{15}$ neutrons $/ \mathrm{cm}^{2}$. Using the exposure ages tabulated in Table 1 for Pasamonte and Forest City, this corresponds to a flux of less than about 20 neutrons $/ \mathrm{cm}^{2}$ sec.

This limit is compatible with the cosmic ray thermal neutron fluxes of less than roughly 0.1 neutron $/ \mathrm{cm}^{2} \mathrm{sec}$, which can be estimated from the calculations of Eberhardt et al. [1963] for small meteoroids (radius $\leqq 25 \mathrm{~cm}$ ) of chondritic composition. 
The Norton County aubrite is a stone remarkable in a number of respects (cf. Table 1): (1) It is the largest stone meteorite existing as a single piece $[\mathrm{Hey}, 1966]$. (2) It has the highest cosmic ray exposure age of all stone meteorites by about a factor of four. (3) Norton County was the first stone meteorite for which an exposure age was determined [Begemann et al., 1957]. Today it is interesting to note that these workers were concerned about the brevity of the $\mathrm{H}^{3}-\mathrm{He}^{3}$ exposure age they found compared to the $\mathrm{K}^{40}-\mathrm{Ar}^{40}$ age of $4.4 \mathrm{~b} . \mathrm{y}$. for this meteorite. (4) The iron content of this meteorite is very low $(\sim 1.6 \%$ total $\mathrm{Fe}[W i i k, 1956])$.

For the study of effects caused by thermal neutrons in meteoritic material, the properties (1), (2), and (4) are essential. A high slowingdown density is necessary for moderating the $\mathrm{Mev}$ secondary neutrons down to thermal energies, and a high exposure age results in a large neutron dosage. Furthermore, neutron capture by $\mathrm{Fe}$ is low.

Table 5 shows that the ratio $\mathrm{Gd}^{128} / \mathrm{Gd}^{157}$ of Norton County is $(0.27 \pm 0.04) \%$ higher than that of terrestrial $\mathrm{Gd}$. This anomaly corresponds to an integrated neutron flux of $(6.3 \pm 0.9) \times$ $10^{15}$ neutrons $/ \mathrm{cm}^{2}$.

Using 600 m.y. as an exposure age for Weekeroo Station [Bogard et al., 1968], an upper limit of 0.2 neutrons $/ \mathrm{cm}^{2} \mathrm{sec}$ is obtained. In view of this comparatively low limit, the presence of large quantities of $\mathrm{Kr}^{\mathrm{s0} \text { end } 82}$ and $\mathrm{Xe}^{129}$ due to epithermal neutron capture on $\mathrm{Br}^{78}$ and 80 and $\mathrm{I}^{127}$, respectively, (D. D. Bogard, J. Huneke, D. S. Burnett, and G. L. Wasserburg, unpublished data, 1969) must be ascribed to a combination of (1) the poor moderating properties of $\mathrm{Fe}$ and $\mathrm{Ni}$ and (2) comparatively large halogen contents for silicate inclusions in iron meteorites.

The experimental evidence is very strong that the neutron effects found in Norton County are caused by cosmic radiation. Burnett et al. [1966] showed that the enrichment of $K^{10}$ in this meteorite is due to the $\mathrm{Ca}^{40}(n, p)$ reaction. The amounts present were smaller than those predicted from the cosmic ray spectrum of Arnold et al. [1961]. Burnett et al. found a $\mathrm{K}^{40}$ production rate for $\mathrm{Ca}^{40}(n, p)$ of about $6 \times 10^{13}$ atoms $\mathrm{K}^{40} / \mathrm{g}$ Ca. For a cross section for the $\mathrm{Ca}^{40} /(n, p)$ reaction of 0.4 barn, this production rate corresponds to an integrated flux of $7.5 \times$
$10^{15}$ neutrons $/ \mathrm{cm}^{2}$. Thus, the ratio of the thermal to Mev neutron flux in Norton County is about 1. A similar calculation for Weekeroo Station yields a thermal to Mev flux ratio of less than $10^{-2}$. This is presumed to be a consequence of the larger size and superior moderating properties of Norton County.

It is possible to obtain an estimate of the epithermal neutron flux in Norton County from rare-gas data by using an indirect approach. The spallation ratio $\mathrm{Ne}^{\mathrm{a}} / \mathrm{He}^{3}$ depends on the hardness of the energy spectrum of the cosmic radiation [Eberhardt et al,, 1966]. Neutrons with energies between ten and a few hundred Mev will induce spallation reactions resulting in small $\Delta A$. Eugster et al. [1969] have shown that the amounts of neutron-produced $\mathrm{Kr}^{80}$ normalized to $1 \mathrm{ppm} \mathrm{Br}$ and $10^{-8} \mathrm{~cm}^{3}$ STP $\mathrm{He}_{\mathrm{spa1}}{ }^{3} / \mathrm{g}$ in ten chondrites are correlated with the spallation ratio $\mathrm{Ne}^{21} / \mathrm{He}^{\mathrm{s}}$. The spallation ratio $\mathrm{Ne}^{\mathfrak{a}} / \mathrm{He}^{3}$ is thus closely related to the epithermal neutron flux $F$ by the empirical equation

$$
F=\frac{s}{\sigma^{78}}\left[\left(\mathrm{Ne}^{21} / \mathrm{He}^{3}\right)_{\mathrm{spa11}}-0.15\right]
$$

The value of $s$ is derived from Figure 10 of Eugster et al. [1969]. We used 110 barns for $\sigma^{79}$ [Marti et al., 1966] for the production of $\mathrm{Kr}^{80}$ by epithermal (30-300 ev) neutron-capture of $\mathrm{Br}^{\mathrm{Ta}}$ and a $\mathrm{He}^{\mathrm{a}}$ production rate of $2 \times 10^{-\mathrm{s}}$ $\mathrm{cm}^{3}$ STP/g m.y. Eberhardt et al. [1965] pointed out that for the same irradiation spectrum $\mathrm{Ne}^{2 \mathrm{z}} /$ $\mathrm{He}^{3}$, ratios are $20 \%$ higher in aubrites than in chondrites, so that the measured spallation ratio $\mathrm{Ne}^{21} / \mathrm{He}^{8}$ for Norton County at 0.26 corresponds to a chondritic value of 0.21. Assuming that $s$ is the same for Norton County and for chondrites, this ratio corresponds to a flux of $3 \times 10^{13}$ neutrons $/ \mathrm{cm}^{2} \mathrm{~m} . \mathrm{y}$. which, with an exposure age of 240 m.y. for Norton County gives an integrated flux of $6 \times 10^{15}$ neutrons/ $\mathrm{cm}^{2}$. Because $s$ should be somewhat higher for Norton County, this value may be somewhat low. Nevertheless, it appears that the neutron fluxes in the three energy ranges considered (thermal, epithermal, and fast) are of the same order of magnitude.

Eberhardt, Geiss, and Lutz [1963] (EGL) have calculated neutron fluxes produced by cosmic rays as a function of position and radius for spherical meteoroids of chondritic composi- 
tion. Because of the low concentrations of heavy elements, particularly Fe, Norton County is an excellent moderator. The estimated resonance escape probability for Norton County is about 0.7 , whereas for chondrites it is 0.1 . This means that the approximations in the EGL calculations are better for Norton County than for chondrites. We assume that the pre-atmospheric radius of Norton County was $50 \mathrm{~cm}$, i.e., approximately the same as its terrestrial size, and that our samples were taken near the present surface at $r=40 \mathrm{~cm}$. (Deep interior samples of Norton County have never been distributed.) Using the 'analytical method' of EGL and making the necessary changes in the parameters to account for the differences from chondritic composition, a flux of 2 neutrons $/ \mathrm{cm}^{2} \mathrm{sec}$ is calculated. This is in good agreement with the measured value of 1.0 neutrons $/ \mathrm{cm}^{2} \mathrm{sec}$. Thus, the EGL calculations and a cosmogenic origin for the Gd isotopic variations in Norton County are mutually consistent. If we consider the cosmogenic origin to be established independently, and if we accept the assumption of similar pre-atmospheric and terrestrial sizes for Norton County, the present experiments provide the first conclusive test of the EGL calculations.

4. Limits on primordial irradiations. For a uniform primordial irradiation (Model $c$ in section 1 under Discussion), limits on the difference in the fraction $q$ of material irradiated can be set. Following the discussion given by Burnett et al. [1966], we obtain a value of $q$ equal or less than 0.001. For example, for a model with $10 \%$ of the solar system material irradiated, this limit would mean that the earth and the meteorites investigated (except Norton County) contain the same proportions of irradiated and unirradiated material to within $1 \%$. These limits are over an order of magnitude lower than those previously set.

\section{Conclusions}

Gd in the Norton County achondrite shows cosmic ray effects induced by the capture of spallation-produced thermal neutrons by $\mathrm{Gd}^{10 \pi}$ and $\mathrm{Gd}^{255}$. The integrated thermal neutron flux corresponding to the anomalies found is $(6.3 \pm$ $0.9) \times 10^{25}$ neutrons $/ \mathrm{cm}^{2}$. The integrated fluxes of epithermal and fast neutrons found based on rare gas data and on $K^{40}$, respectively, are of the same order of magnitude. The possibility of detecting neutron anomalies of $0.1 \%$ in samples of about $10^{-8}$ gram Gd provides us with an important technique for the study of the history of the lunar surface.

All other iron and stone meteorites investigated in this work contain Gd with the same isotopic composition as terrestrial Gd. This places an upper limit of $3 \times 10^{15}$ neutrons $/ \mathrm{cm}^{2}$ for a differential primordial thermal neutron irradiation of the earth and the meteorites.

Acknowledgments. We wish to thank Hannelore and Uwe Derksen for their able technical assistance and John Huneke and Günther Lugmair for useful comments on the manuscript. We are grateful to our colleagues who supplied meteorite samples used in this work: Norton County, Pasamonte, Forest City, and Weekeroo Station were obtained from the Nininger Meteorite Collection at the Arizona State University through the aid of C. B. Moore. Copiapo was supplied by Drs. P. Pellas, J. Orcel and F. Kraut of the Paris Natural History Museum.

This work was supported by National Science Foundation grants GP 9433 and GP 9114.

\section{REFERENCES}

Arnold, J. R., M. Honda, and D. Lal, Record of cosmic-ray intensity in the meteorites, $J$. GeoPhys. Res., 66, 3519, 1961.

Begemann, F., J. Geiss, and D. C. Hess, Radiation age of a meteorite from cosmic ray-produced $\mathrm{He}^{\mathrm{a}}$ and $\mathrm{H}^{3}$, Phys. Rev., 107, 540, 1957.

Bogard, D. D., D. S. Burnett, P. Eberhardt, and G. J. Wasserburg, $\mathrm{Ar}^{40}-\mathrm{K}^{40}$ ages of silicate inclusions in iron meteorites, Earth Planetary Sci. Letters, 3, 275, 1968.

Burnett, D. S., W. A. Fowler, and F. Hoyle, Nucleosynthesis in the early history of the solar system, Geochim. Cosmochim. Acta, 29, 1209, 1965 .

Burnett, D. S., H. J. Lippolt, and G. J. Wasserburg, The relative isotopic abundance of $\mathrm{K}^{4 c}$ in terrestrial and meteoritic samples, J. Geophys. Res., $71,1249,1966$.

Collins, T. L., F. M. Rourke, and F. A.. White, Mass spectrometric investigation of the rareearth elements for the existence of new stable isotopes, Phys. Rev., 105, 196, 1957.

Daniels, Farrington, Comment, in Proceedings of the Conference on Nuclear Processes in Geologic Settings, Williams Bay, Wisconsin, p. 35, National Research Council, 1953

Eberhardt, P., O. Eugster, and J. Geiss, Radiation ages of aubrites, J. Geophys. Res., 70, 4427, 1965.

Eberhardt, P., O. Eugster, J. Geiss, and K. Marti, Rare gas measurements in 30 stone meteorites, Z. Naturforsch., 21a, 414, 1966.

Eberhardt, P., J. Geiss, and H. Lutz, Neutrons in 
meteorites, in Earth Science and Meteorites, edited by J. Geiss and E. D. Goldberg, p. 143, North-Holland, Amsterdam, 1963.

Eugster, O., P. Eberhardt, and J. Geiss, Isotopic analyses of krypton and xenon in fourteen stone meteorites, J. Geophys. Res., 74, 3874, 1969.

Eugster, O., F. Tera, and G. J. Wasserburg, Isotopic analysis of barium in meteorites and in terrestrial samples, J. Geophys. Res. 74, 3897, 1969.

Fowler, W. A., J. L. Greenstein, and F. Hoyle, Nucleosynthesis during the early history of the solar system, Geophys. J., 6, 148, 1962.

Haskin, L. A., F. A. Frey, R. A. Schmitt, and R. H. Smith, Meteoritic, solar, and terrestrial rare earth distributions in Physics and Chemistry of the Earth, Pergamon Press, Oxford and New York, 1966.

Hey, M. H., Catalogue of Meteorites, 3rd ed., British Museum, London, 1966.

Kirsten, T., D. Krankowsky, and J. Zähringer, Edelgas- und Kalium-Bestimmungen an einer grösseren Zahl von Steinmeteoriten, Geochim. Cosmochim. Acta, 27, 13, 1963.
Marti, K., P. Eberhardt, and J. Geiss, Spallation, fission, and neutron capture anomalies in meteoritic krypton and xenon, Z. Naturforsch, 21a, 398, 1966.

Møller, H. B., F. J. Shore, and V. L. Sailor, Low energy neutron resonances in erbium and gadolinium, Nucl. Sci. Eng., 8, 183, 1960.

Murthy, V. R., and R. A. Schmitt, Isotope abundances of rare-earth elements in meteorites, $J$. Geophys. Res., 68, 911, 1963.

Nier, A. O., A redetermination of the relative abundances of the isotopes of carbon, nitrogen, oxygen, argon, and potassium, Phys. Rev., 77, $789,1950$.

Wasserburg, G. J., D. A. Papanastassiou, E. V. Nenow, and C. A. Bauman, A programmable magnetic field mass spectrometer with on-line data processing, Rev. Sci. Instr., 40, 288, 1969.

Wiik, H. B., The chemical composition of some stony meteorites, Geochim. Cosmochim. Acta, 9, 279, 1956.

(Received November 24, 1969; revised February 3, 1970.) 